\title{
A Model for Urban Environment and Resource Planning Based on Green GDP Accounting System
}

\author{
Linyu Xu, Bing Yu, Wencong Yue, and Xiaodong Xie \\ State Key Joint Laboratory of Environmental Simulation and Pollution Control, School of the Environment, \\ Beijing Normal University, 19 Xinjiekouwai Street, Haidian District, Beijing 100875, China
}

Correspondence should be addressed to Linyu Xu; xly@bnu.edu.cn

Received 5 December 2012; Accepted 8 March 2013

Academic Editor: Yongping Li

Copyright (C) 2013 Linyu Xu et al. This is an open access article distributed under the Creative Commons Attribution License, which permits unrestricted use, distribution, and reproduction in any medium, provided the original work is properly cited.

The urban environment and resources are currently on course that is unsustainable in the long run due to excessive human pursuit of economic goals. Thus, it is very important to develop a model to analyse the relationship between urban economic development and environmental resource protection during the process of rapid urbanisation. This paper proposed a model to identify the key factors in urban environment and resource regulation based on a green GDP accounting system, which consisted of four parts: economy, society, resource, and environment. In this model, the analytic hierarchy process (AHP) method and a modified Pearl curve model were combined to allow for dynamic evaluation, with higher green GDP value as the planning target. The model was applied to the environmental and resource planning problem of Wuyishan City, and the results showed that energy use was a key factor that influenced the urban environment and resource development. Biodiversity and air quality were the most sensitive factors that influenced the value of green GDP in the city. According to the analysis, the urban environment and resource planning could be improved for promoting sustainable development in Wuyishan City.

\section{Introduction}

During the process of rapid urbanisation, many countries or regions excessively pursue economic development goals like gross domestic product (GDP) (GDP, an important indicator of the economic development level of a country, is the monetary value of all final goods and services produced in a country over a period of 1 year), while ignoring the integrity of the urban ecosystem. As a result, cities are confronted with increasingly relevant biophysical limitations due to the deterioration of natural resources and the environment during these periods of impressive economic growth [1]. Because of this deterioration, various regulations have targeted the urban environment and resource protection to make cities more ecologically resilient [2-5]. Within the relevant studies, the general idea of urban ecological regulation is to recognise the main ecological problems during urban development and then solve them through ecological planning $[6,7]$. However, there are few efficient quantitative methods for coordinating the relationship between urban economic development and environmental resource protection in previous studies.
In fact, it is efficient to manage the environment and resources by methods of economic regulation. In this vein, green GDP is a general indicator of economic regulation for environmental protection and resource protection. Measuring green GDP can also be used by environmentalists to track the provision of nature's benefits over time to hold governments accountable or to compare environmental conditions among different cities [8].

Green GDP accounting conventions can be classified into two main groups [9]. Type I green GDP takes into account the difference between GDP and the cost of environmental pollution and resource depletion, but the value of natural ecosystem services is ignored. Heal noted that national economic accounts need to present income statements and balance sheets that reflect the value of ecosystem services [10]. In this context, more scholars have begun to account for the value of ecosystem services and include it in GDP accounting, which we refer to as type II green GDP. Type I green GDP can promote the control of emissions by pollution producers, and therefore is suitable for accounting for green GDP for typical polluted cities. Type II green GDP encourages households 
to protect the ecoenvironment and is therefore suitable for application to typical cities with better natural environmental conditions. Of the two types, type II green GDP includes the benefits from the protection of natural ecosystems and has been widely studied in recent years.

The original notion of type II green GDP accounting came from research by Costanza et al. in which the value of global ecosystem services was compared with global GNP. After that, the idea of including ecoservice valuation in traditional economic accounting systems was proposed and gradually developed [11-13]. In 2005, the Millennium Ecosystem Assessment [14] used the notion of ecosystem services to research type II green GDP accounting, and in 2007, Boyd and Banzhaf [15] defined the concept of final ecosystem services and used these as standardised environmental accounting units. However, type II green GDP accounting is still in its infancy, and the approach used to define and calculate final ecosystem services is a key issue.

As argued in a report by the Commission on the Measurement of Economic Performance and Social Progress [16], "green GDP constitutes only one aspect of sustainability, and more research on sustainability assessment is required." On one hand, these green GDP accounting methods, especially the type II method, need to be further improved. Existing accounting methods have focused on accounting for ecoservices, but cannot be easily combined with traditional GDP accounting systems. In China, green GDP accounting systems have included the value of ecosystem services [17], but the accuracy and rationality of ecosystem services accounting do not meet requirements for green GDP accounting. On the other hand, most studies of green GDP still focus on value accounting methods rather than their application. The importance of green GDP should not be limited to calculating a numerical value. Rather, approaches for applying green GDP to reality, such as in urban ecosystem construction or environmental management, should be the focus of more studies.

In this context, a traditional GDP accounting system was decomposed in the present study according to the character of the national economic accounting system in China; it was adapted into a green GDP accounting system including direct ecosystem services; this system was the basis for the urban environment and resource regulation model in this paper. The AHP method and a modified Pearl curve model were then used to identify the key factors in the green GDP accounting system for urban environment and resource regulation; dynamic evaluation was performed, where a higher value of green GDP was the planning target. In this paper, these efforts were demonstrated by a case study of Wuyishan City, and six effective ecological projects were put forward to promote its urban sustainable development.

\section{Methodology}

2.1. Green GDP Accounting System. Traditional GDP in China was calculated for 20 different industry categories (e.g., agriculture, forestry, animal husbandry, fishing, and Appendix) according to the National Bureau of Statistics.
These industries can be classified into three types according to their features, and thus GDP can be divided into three parts:

$$
k_{1} \mathrm{GDP}+k_{2} \mathrm{GDP}+k_{3} \mathrm{GDP}=\mathrm{GDP},
$$

where $k_{1}, k_{2}$, and $k_{3}$ represent the proportion of GDP generated by economic, social, and resource systems, respectively. However, the environment, which is very important for urban development, is not considered in this equation. Thus, green GDP may be a more suitable metric and can be decomposed as follows:

$$
\begin{aligned}
& \text { Green } \mathrm{GDP}_{2}=k_{1} \mathrm{GDP}+k_{2} \mathrm{GDP}+k_{3} \mathrm{GDP}+\mathrm{DES} \text {, } \\
& \mathrm{DES}+\mathrm{ES}_{1}+\mathrm{ES}_{2}=\mathrm{ESP}
\end{aligned}
$$

where green $\mathrm{GDP}_{2}$ is type II green GDP and DES is direct ecosystem services, which can be calculated as final consumption of GDP using the expenditure method. ESP is ecosystem services product, $\mathrm{ES}_{1}$ is ecosystem benefits for other creatures, and $\mathrm{ES}_{2}$ is ecosystem benefits for future generations. Therefore, (2) can be simplified to

$$
\text { Green } \mathrm{GDP}_{2}=\mathrm{GDP}+\mathrm{DES} \text {. }
$$

Because the proportion of the components can differ over time and for different cities or regions, $k_{1}, k_{2}$, and $k_{3}$ are not constant and need to be determined for specific cases. DES is part of the total ecosystem services; thus, we need to first determine the DES types (Figure 1) that should be selected. The selection principles are as follows.

(1) Both humans and other creatures will enjoy ecological benefits provided by the natural ecosystem. Therefore, ecosystem services to humans and other creatures should be treated separately in green GDP accounting.

(2) The ecosystem services selected must be end products consumed by humans within a certain period of time to meet GDP accounting requirements. In this study, services are only considered for humans.

Ecosystem services can be divided into those yielding contemporaneous human benefits, descendant benefits, and benefits for all creatures. The benefits for contemporary human included the ecosystem services which were consumed by mankind only in the present. The benefits for all creatures referred to the ecosystem services which can be enjoyed by all creatures, not limited to mankind. The benefits for descendant were the supports for sustainable development provided by ecosystem services.

Based on the selection principles, only the part of services yielding benefits for all creatures should be included in green GDP. Services that yield future human benefits belong to neither DES nor to green GDP. Services accounted for in GDP, such as food production, water supply, and raw material supply, should be excluded. This is a general division of the ecosystem, and the division can be varied for different regions or different periods. 


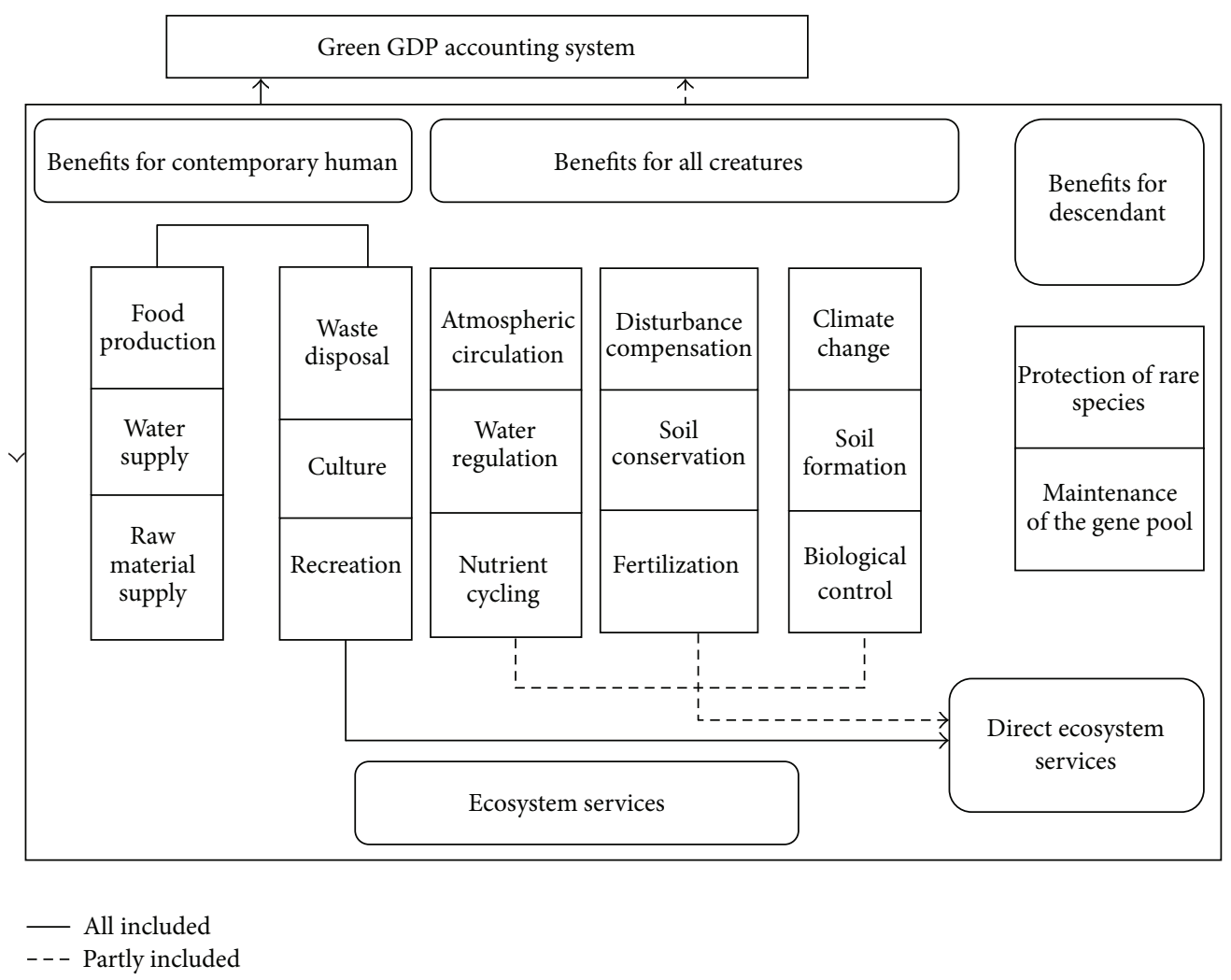

FigURE 1: Green GDP accounting system.

Reasonable accounting methods are chosen to calculate the value of direct ecosystem services, such as the hedonic price method for aesthetic valuation and the market price method for water conservation. Thus, the value of DES and green GDP can be obtained.

\subsection{Environment and Resource Regulation Model}

2.2.1. Key Factors Analysis with AHP Method. The value of green GDP is influenced by multiple factors in environmental, social, and economic systems. Therefore, beyond accounting for values, a comprehensive analysis should be done by various influenced factors. We selected key factors and analysed them using AHP method (see Figure 2).

2.2.2. Sensitivity Analysis with Pearl Curve Model. The interactions among social, economic, environmental managerial, regulatory, and lifestyle factors are complicated and change over time [18]. Therefore, to identify improvements in ecosystem services and human activities, the impact of human activities on ecological factors and green GDP should be analysed dynamically. The Pearl curve model was widely used to show the variations $[19,20]$, mathematically expressed as:

$$
l=\frac{L}{1+a e^{-b t}},
$$

where $l$ is the variation index for the factor, $L$ is its maximum value, $a$ and $b$ are constants, and $t$ is a parameter reflecting differences in the factor over time.
With reference to the form of Pearl curve, we established a modified Pearl curve model to express the influence of ecological factors and ecosystem services, mathematically expressed as:

$$
l=\frac{L}{1+e^{-t}}-\frac{1}{2} .
$$

In this model, it insured that in the beginning $(t=0)$, when the situation of human activities and the ecological situations was retention (R), the change were equal to 0 . Moreover, the model was symmetric about the $x$-axis, in order to make the influence of ecological factors and ecosystem services more clear and comparative.

Therefore, the models for changes in ecological factors and green GDP are:

$$
\begin{aligned}
& l_{1}=\frac{L_{1}}{1+e^{-t_{1}}}-\frac{1}{2}, \\
& l_{2}=\frac{L_{2}}{1+e^{-t_{2}}}-\frac{1}{2},
\end{aligned}
$$

where $l_{1}$ is the change in ecological factor, $L_{1}$ is the maximum value for the ecological factor, and $t_{1}$ denotes the situation for human activities, with $t_{1}=-3,-2,-1,0,1,2$ and 3 indicating high deterioration (HD), moderate deterioration (MD), slight deterioration (SD), retention (R), slight improvement (SI), improvement (I), and entire improvement (EI), respectively. Similarly, $l_{2}$ is the change in green GDP, $L_{2}$ is 


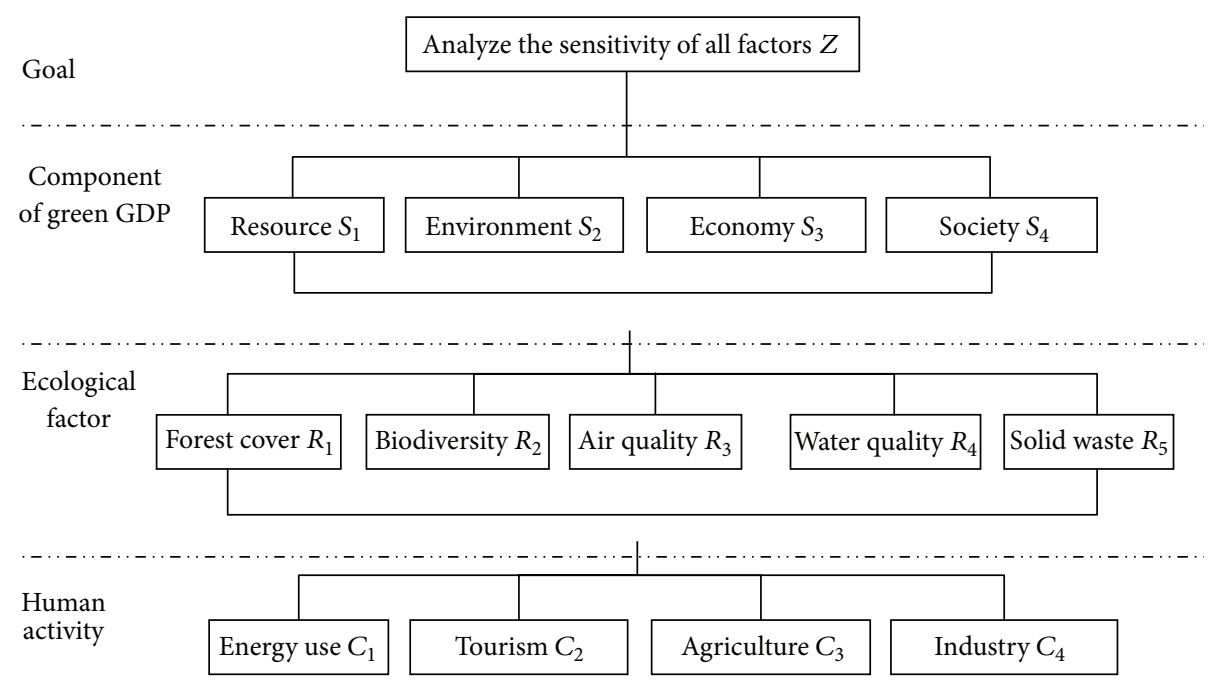

FIGURE 2: Hierarchical structure for key factors in green GDP accounting.

the maximum value of green GDP, and $t_{2}$ denotes the situation for ecological factors, with $t_{2}=-3,-2,-1,0,1,2$ and 3 indicating $\mathrm{HD}, \mathrm{MD}, \mathrm{SD}, \mathrm{R}, \mathrm{SI}, \mathrm{I}$, and $\mathrm{EI}$, respectively.

According to the key factors analysis and sensitivity analysis for green GDP accounting, the relationships between human activities and green GDP and ecological factors and green GDP can be revealed; thus, environmental and resource planning can be proposed for improving green GDP.

\section{Case Study}

3.1. Study Area. Wuyishan City is located in the northwest of Fujian Province, China, and consists of three districts and seven towns. It covers a total area of approximately $2802.77 \mathrm{~km}^{2}$ (Figure 3). It is a popular with tourists because of Mount Wuyi, which is included on the UNESCO World Heritage List (http://whc.unesco.org/en/list/911). Wuyishan Nature Reserve has the largest existing and best-preserved subtropical native forest ecosystem. To protect this important ecological environment, the authorities in Wuyishan City have limited industrial development, despite the GDP benefits of industrial production.

For Wuyishan City, the environmental externality mainly came from its good ecoenvironment; the valuation of its forest ecosystem services should be accounted well with type II green GDP. Therefore, type II green GDP accounting is suitable for encouraging the government and households of Wuyishan City to protect the natural environment.

3.2. Green GDP Accounting for Wuyishan City. The DES selection was based on the analysis of leading industries and the opinions of local residents. It not only considers current social economic situation, but also the individual's ecological consciousness. This process can also provide a reference for analysis of the key factors in green GDP accounting and ecological regulation in subsequent research.
3.2.1. Leading Industries. A ratio method can be used to select the leading industry according to the following:

$$
S V_{i j}=\frac{\left(V_{i j} / V_{i}\right)}{\left(V_{j} / V\right)},
$$

where $S V_{i j}$ is an index representing the status of an industry in the regional economy, $V_{i j}$ is the value added by industry $j$ in region $i, V_{i}$ is the total value added for region $i, V_{j}$ is the total value added by industry $j$, and $V$ is the national gross value added. $S V_{i j}>1$ means that industry $j$ is a leading industry in region $i$.

According to (8), the value of $S V_{i j}$ for each industry in Wuyishan City is shown in Table 1.

The data in Table 1 show that tourism has the highest $S V_{i j}$ value, which reflects the predominant role of tourism in the economy of Wuyishan City. Manufacturing industry has the lowest $S V_{i j}$ value, which confirms that local industrial development is low. These results properly reflect the character of Wuyishan City, which has strict environmental protection requirements. Hence, type II green GDP accounting, which reflects changes in the welfare of local residents and fully internalized market externalities for Wuyishan City, is more appropriate than type I green GDP.

3.2.2. Opinion of Local Residents. Based on the meaning of ESI, the DES was determined according to the urban ecosystem characteristics and the opinions of local residents. Through questionnaire surveys, the residents' attitudes toward and understanding of local ecosystem services were elicited.

Researchers conducted questionnaire surveys over a period of 15 days to investigate the ecological and environmental consciousness of the residents in Wuyishan City. Respondents were randomly selected from different towns within Wuyishan City and 361 questionnaires were returned. The third and fourth questions in the questionnaire focused 


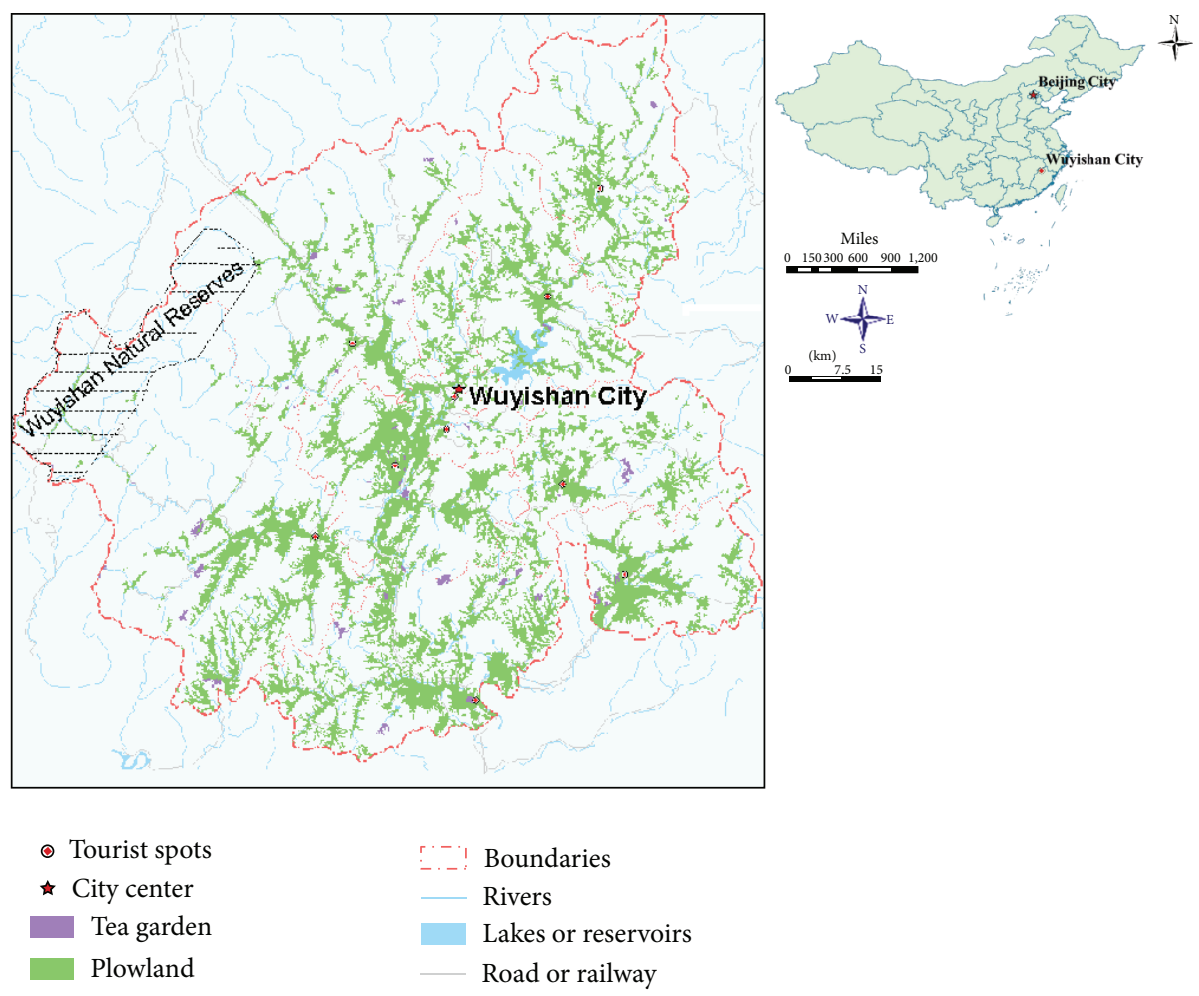

Figure 3: Location of Wuyishan City, China.

TABLE 1: $S V_{i j}$ for each industry in Wuyishan City.

\begin{tabular}{lccc}
\hline Item & $\begin{array}{c}\text { National } \\
\left(10^{8} \text { yuan }\right)\end{array}$ & $\begin{array}{c}\text { Wuyishan city } \\
\left(10^{4} \text { yuan }\right)\end{array}$ & $S V_{i j}$ \\
\hline GDP & 335353 & 556423 & - \\
Primary industry & 35477 & 109709 & 1.863771 \\
Secondary industry & 156958 & 178303 & 0.684656 \\
Manufacturing industry & 134625 & 114603 & 0.513059 \\
Construction & 22333 & 63700 & 1.719054 \\
Tertiary industry & 142918 & 278411 & 1.174077 \\
Tourism & 10184 & 303200 & 17.94353 \\
\hline
\end{tabular}

on attitudes toward and understanding of ecosystem services (Figure 4).

Some $35.3 \%$ of the respondents hoped that local tourism would be a priority for development, and 31.5\% believed that parks should be built in vacant lots. These responses indicate that local residents are concerned about the recreation services provided by Wuyishan Scenic Spots and Nature Reserve.

According to the analysis and questionnaire results, the importance of six human benefit types (food production, water supply, aesthetic, health guarantee, reduced waste treatment costs, and culture) was confirmed. Because the first two were already included in the traditional GDP accounting system, they were excluded to avoid repeat accounting. The other four benefits were included in green GDP. The DES composition is shown in Figure 5.
After collecting relevant data, the accounting methods listed in Table 2 [21] were used to calculate the value of direct ecosystem services for Wuyishan City (Table 3 ).

Among DES types, the largest value was observed for water conservation (65\%), followed by gas regulation (29\%). This shows that the natural landscape of Wuyishan City not only promotes local tourism development but also provides many benefits for residents that cannot be ignored in GDP accounting systems. Therefore, protection of the natural environment should be strengthened when focusing on the development of local tourism.

According to the type II green GDP accounting model, the green GDP of Wuyishan City from 2005 to 2010 was calculated in Table 4.

The green GDP in Wuyishan City has risen gradually in the past years. As the direct ecosystem service value of Wuyishan City has changed little, the trend growth of green GDP and GDP kept pace. The results indicated that the economic development in Wuyishan City has coordinated with its environment and resource protection. But it is necessary to pay more attention to protect its environment and resources to increase its green GDP.

3.3. Environment and Resource Regulation for Wuyishan City. Using an analytic hierarchy process (AHP) method, we built the hierarchical structure (Figure 5) to analyse the correlations among resources, environment, economy, and society that form the important aspects of ecological factors and human activity. According to the hierarchical structure, 
TABLE 2: Accounting method for each direct ecosystem service (DES).

\begin{tabular}{|c|c|c|}
\hline DES & Method & Formula \\
\hline Aesthetic & Hedonic pricing & $\begin{array}{l}\text { Trees can increase real estate prices by } 5-10 \% \text {, which can be a basis for accounting for aesthetic } \\
\text { value }\end{array}$ \\
\hline Water conservation & Market price & $\begin{array}{l}\mathrm{DES}_{1}=(R-E) \times A \times E p \text {, } \\
\text { where } \mathrm{DES} S_{1} \text { is the water restoration per unit area, yuan } /\left(\mathrm{hm}^{2} \cdot \mathrm{yr}\right), R \text { is average rainfall, } \mathrm{mm} / \mathrm{yr} \text {, } \\
E \text { is average evaporation, } \mathrm{mm} / \mathrm{yr}, A \text { is the study area }\left(\mathrm{hm}^{2}\right) \text {, and } E p \text { is the shadow price of } \\
\text { water, } 0.67 \text { yuan } / \mathrm{m}^{3}\end{array}$ \\
\hline \multicolumn{3}{|l|}{ Gas regulation } \\
\hline $\mathrm{SO}_{2}$ absorption & Shadow price & $\begin{array}{l}\mathrm{DES}_{2}=\mathrm{Q} d_{2} \times C d_{2} \times S, \\
\left.\text { where } \mathrm{DES} S_{2} \text { is the value of absorbing } \mathrm{SO}_{2} \text { of per unit area of ecosystem, yuan/(hm² } \cdot \mathrm{yr}\right), \mathrm{Qd} d_{2} \text { is } \\
\text { ability of } \mathrm{SO}_{2} \text { absorption of per unit area of ecosystem, ton/( }\left(\mathrm{hm}^{2} \cdot \mathrm{yr}\right), C d_{2} \text { is the engineering } \\
\text { cost for reducing } \mathrm{SO}_{2}, 1090 \text { yuan/ton, and } S \text { is the study area acreage }\left(\mathrm{hm}^{2}\right) .\end{array}$ \\
\hline $\begin{array}{l}\text { Reducing particulate } \\
\text { matter (PM) }\end{array}$ & Substitute cost & $\begin{array}{l}\mathrm{DES} S_{3}=Q d_{3} \times C d_{3} \times S, \\
\text { where } \mathrm{DES} S_{3} \text { is the value of reducing PM per unit area, yuan } /\left(\mathrm{hm}^{2} \cdot \mathrm{yr}\right), Q d_{3} \text { is the ability to } \\
\text { reduce } \mathrm{PM} \text { per unit area, } \mathrm{t} /\left(\mathrm{hm}^{2} \cdot \mathrm{yr}\right), C d_{3} \text { is the cost of reducing } \mathrm{PM}, 170 \text { yuan/ton, and } S \text { is the } \\
\text { study area }\left(\mathrm{hm}^{2}\right)\end{array}$ \\
\hline Cultural & - & $\begin{array}{l}\text { The average scientific cultural value of the global temperate forest ecosystem is } \\
99 \text { yuan } /\left(\mathrm{hm}^{2} \cdot \text { year }\right)\end{array}$ \\
\hline
\end{tabular}

TABle 3: Value of direct ecosystem services in Wuyishan City in 2010.

\begin{tabular}{lc}
\hline Type of service & Value $\left(10^{4}\right.$ yuan $)$ \\
\hline Aesthetic & 6164 \\
Water conservation & 93670 \\
Gas regulation & 41605 \\
Cultural & 2269 \\
\hline Total value & 143708 \\
\hline
\end{tabular}

The total forest area in Wuyishan City was $229191.33 \mathrm{hm}^{2}$ in 2010 (land use plan of Wuyishan City, 2006-2020).

TABLE 4: Green GDP in Wuyishan City from 2005 to 2010 ( $10^{4}$ yuan).

\begin{tabular}{lcccccc}
\hline Year & 2005 & 2006 & 2007 & 2008 & 2009 & 2010 \\
\hline DES & 138947 & 139505 & 139837 & 141125 & 141858 & 143708 \\
GDP & 301818 & 339237 & 416641 & 493920 & 556423 & 657789 \\
Green GDP & 440765 & 478742 & 556478 & 635045 & 698281 & 801497 \\
\hline
\end{tabular}

Data resource: Statistical bulletin of national economic and social development in Wuyishan, China (2005-2010); land use plan of Wuyishan City, 2006-2020.

TABLE 5: Value of direct ecosystem services in Wuyishan City in 2010.

\begin{tabular}{lcccc}
\hline Item & Energy use & Agriculture & Tourism & Industry \\
\hline Forest cover & 0.201 & 0.441 & 0.455 & 0.231 \\
Biodiversity & 0.078 & 0.062 & 0.455 & 0.077 \\
Air quality & 0.520 & 0.166 & 0.000 & 0.231 \\
Water quality & 0.000 & 0.166 & 0.000 & 0.231 \\
Solid waste & 0.201 & 0.166 & 0.091 & 0.231 \\
\hline
\end{tabular}

the pairwise comparison matrices for each layer were constructed based on our survey conducted in Wuyishan City. The weights for the impact of human activities on ecological factors and of ecological factors on green GDP are presented in Tables 5 and 6.

The impact weights can be divided into four grades: 0-0.25 (no influence), grade I; 0.26-0.5 (slight influence), grade II; $0.51-0.75$ (large influence), grade III; and $0.76-1$ (enormous influence), grade IV.

The standards for human activities and ecological factors changes were classified according to (6) and are shown in Table 7 .

The effects of changes in human activities on ecological factors can be calculated based on Tables 5 and 7; the data are multiplied by the corresponding numerical values. The results are shown in Table 8 and Figure 6.

Similarly, the effects of changes in ecological factors on green GDP can be calculated based on Tables 6 and 7. According to the weight for green GDP components (Table 9), the results are shown in Table 10 and Figure 7.

According to the results in Tables 8 and 10, human activities impact green GDP. These effects are shown in Table 11 and Figure 8.

According to our analysis, green GDP was most sensitive to biodiversity and energy use, followed by air quality and tourism. The results suggest that human activities have a significant influence on the green GDP of Wuyishan City and could be considered as key factors in ecological regulation. Based on these key factors, ecological projects can be carried out to regulate the ecological functioning of the region and increase the value of green GDP; some examples of possible projects include nature reserve division construction, corridor building restoration of ecological landscapes, rural biogas planning, vehicle control and improvements, and regulation of industrial energy.

3.4. Discussion. In this case study, we calculated Wuyishan City's green GDP in recent past years and applied the proposed models to identify the key factors of environment and resource planning for its ecological construction. Although 


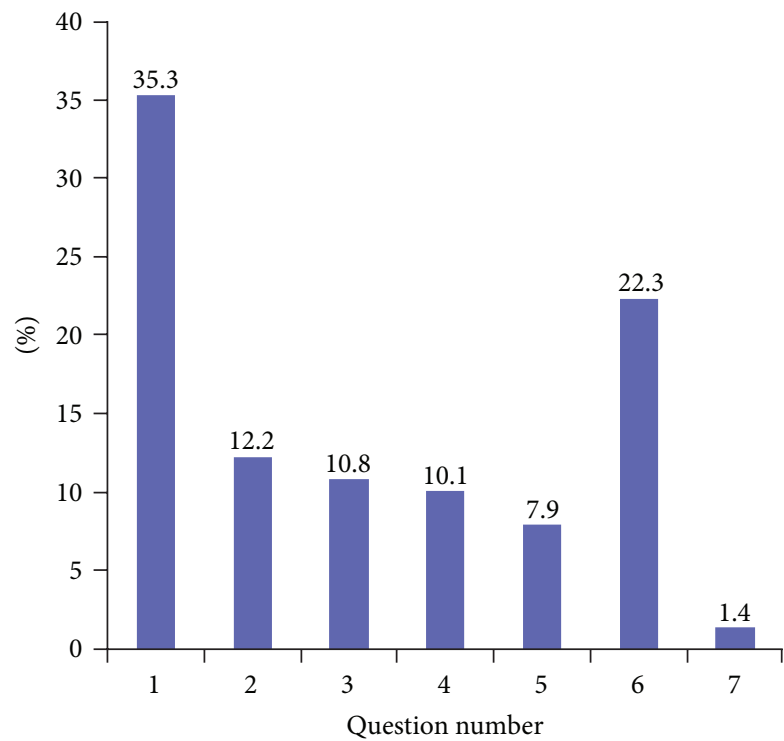

Percent

Q3. What would you prefer to be continuously developed in Wuyishan City after 5 years:
(1) Tourism
(5) Transportation
(2) Industry
(6) Education
(3) Agriculture
(7) Other
(4) Service industry

(a)

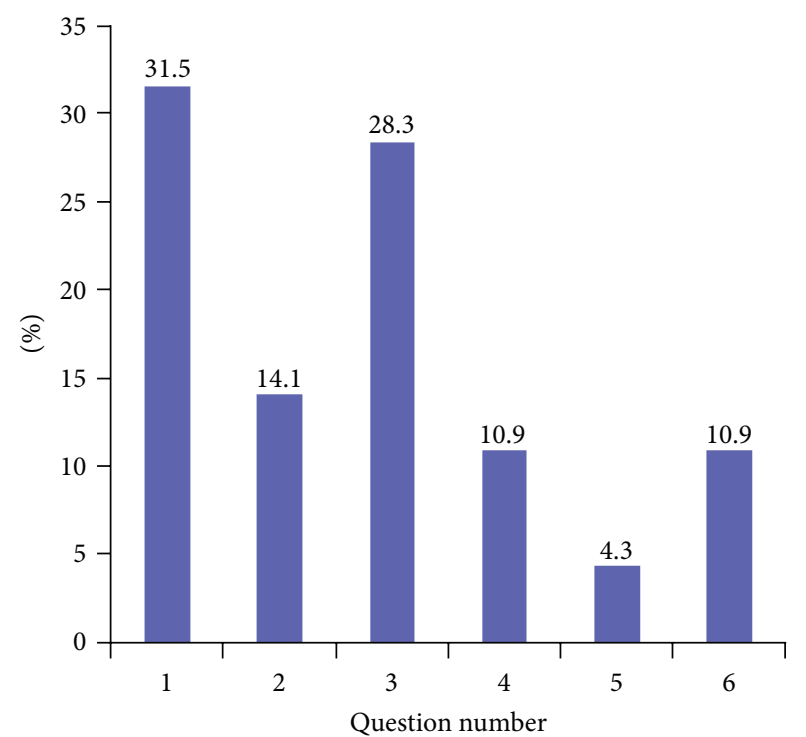

Percent

Q4. If you owned a piece of land in Wuyishan City, what would you build?
(1) Park
(4) Farmstead
(2) Housing
(5) Other
(3) Factory
(6) Not sure

(b)

Figure 4: The third and fourth questions in the questionnaire.

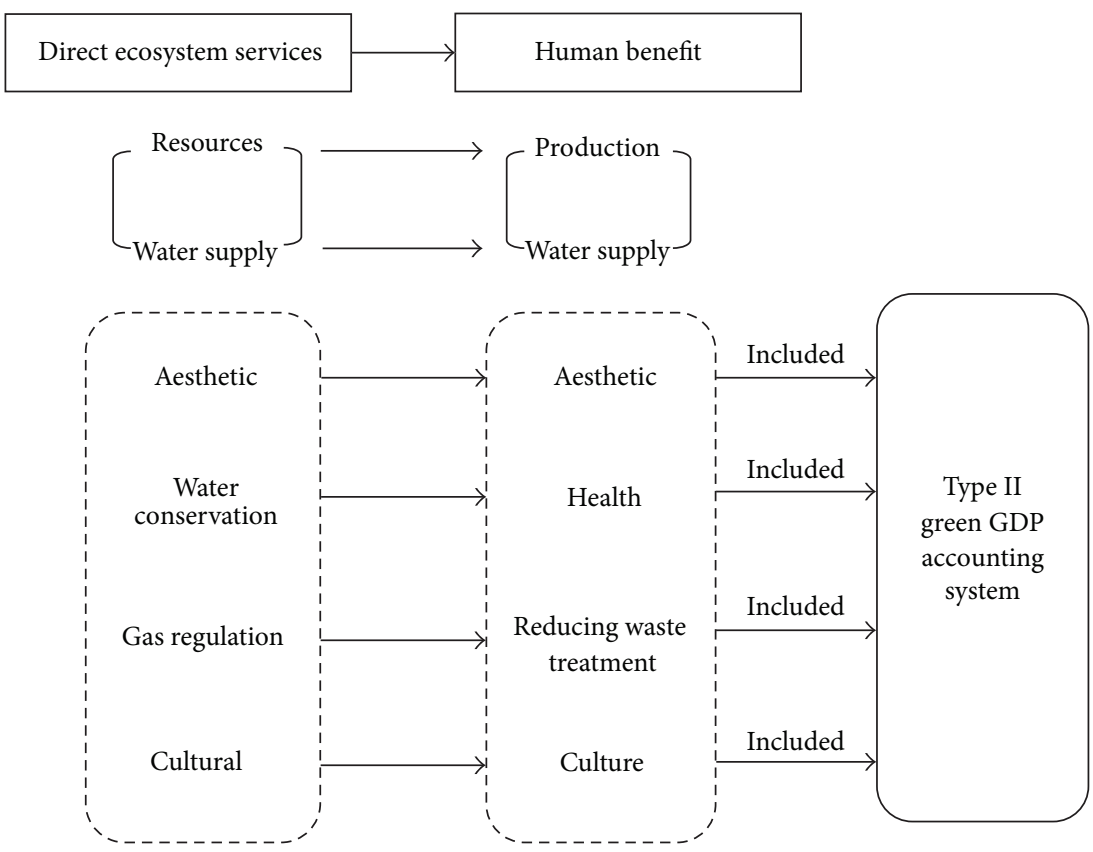

FIgURe 5: Direct ecosystem services for Wuyishan City. 
TABLE 6: Weights for the impact of ecological factors on green GDP components.

\begin{tabular}{|c|c|c|c|c|c|}
\hline Item & Forest cover & Biodiversity & Air quality & Water quality & Solid waste \\
\hline Resource & 0.138 & 0.086 & 0.105 & 0.375 & 0.109 \\
\hline Environment & 0.545 & 0.153 & 0.159 & 0.125 & 0.109 \\
\hline Economy & 0.233 & 0.522 & 0.512 & 0.375 & 0.297 \\
\hline Society & 0.084 & 0.239 & 0.225 & 0.125 & 0.484 \\
\hline
\end{tabular}

TABLE 7: Standards for changes in factors.

\begin{tabular}{lcccc}
\hline \multirow{2}{*}{ Change $y$} & \multicolumn{4}{c}{ Impact grade } \\
& I & II & III & IV \\
\hline HD $y_{7}$ & -0.4517 & -0.9033 & -1.3550 & -1.8066 \\
MD $y_{6}$ & -0.3794 & -0.7587 & -1.1381 & -1.5175 \\
SD $y_{5}$ & -0.2297 & -0.4595 & -0.6892 & -0.9189 \\
R $y_{4}$ & 0.0000 & 0.0000 & 0.0000 & 0.0000 \\
SI $y_{3}$ & 0.2297 & 0.4595 & 0.6892 & 0.9189 \\
I $y_{2}$ & 0.3794 & 0.7587 & 1.1381 & 1.5175 \\
EI $y_{1}$ & 0.4517 & 0.9033 & 1.3550 & 1.8066 \\
\hline
\end{tabular}

TABLE 8: Standards for changes in ecological factors as a function of human activities.

\begin{tabular}{lcccc}
\hline & \multicolumn{3}{c}{ Changes in ecological factors } \\
& Energy use & Agriculture & Tourism & Industry \\
\hline HD $(-3)$ & $-0.921 L_{1}$ & $-0.651 L_{1}$ & $-0.863 L_{1}$ & $-0.452 L_{1}$ \\
MD (-2) & $-0.774 L_{1}$ & $-0.547 L_{1}$ & $-0.725 L_{1}$ & $-0.380 L_{1}$ \\
SD (-1) & $-0.469 L_{1}$ & $-0.331 L_{1}$ & $-0.439 L_{1}$ & $-0.230 L_{1}$ \\
R (0) & $0.000 L_{1}$ & $0.000 L_{1}$ & $0.000 L_{1}$ & $0.000 L_{1}$ \\
SI (1) & $0.469 L_{1}$ & $0.331 L_{1}$ & $0.439 L_{1}$ & $0.230 L_{1}$ \\
I (2) & $0.774 L_{1}$ & $0.547 L_{1}$ & $0.725 L_{1}$ & $0.380 L_{1}$ \\
EI (3) & $0.921 L_{1}$ & $0.651 L_{1}$ & $0.863 L_{1}$ & $0.452 L_{1}$ \\
\hline
\end{tabular}

TABLE 9: Proportion for green GDP components in 2010.

\begin{tabular}{lcc}
\hline Component & Value $\left(10^{4}\right.$ yuan $)$ & Proportion $(\%)$ \\
\hline Resource $S_{1}\left(k_{3}\right.$ GDP $)$ & 206569 & 25.8 \\
Environment $S_{2}(\mathrm{DES})$ & 143708 & 17.9 \\
Economy $S_{3}\left(k_{1} \mathrm{GDP}\right)$ & 399199 & 49.8 \\
Society $S_{4}\left(k_{2} \mathrm{GDP}\right)$ & 52021 & 6.5 \\
Green GDP & 801497 & 100 \\
\hline
\end{tabular}

Date source is based on Nanping monthly statistics in Fujian Province, China, 2010.

we have got the specific results, some uncertainties and limitation need to further discussion.

For green GDP accounting system, as it mentioned that the division of direct ecosystem services can be varied for different regions or different periods. In the case study, according to Wuyishan City's geographical feature, the DES selection was largely due to its typical forest ecosystem, and we assumed that in the past 6 years, from 2005 to 2010, the local people's ecological consciousness changed little.

In the regulation model, the key factors for environment and resource planning were identified by the AHP method; further, the sensitivities of the key factors were analysed

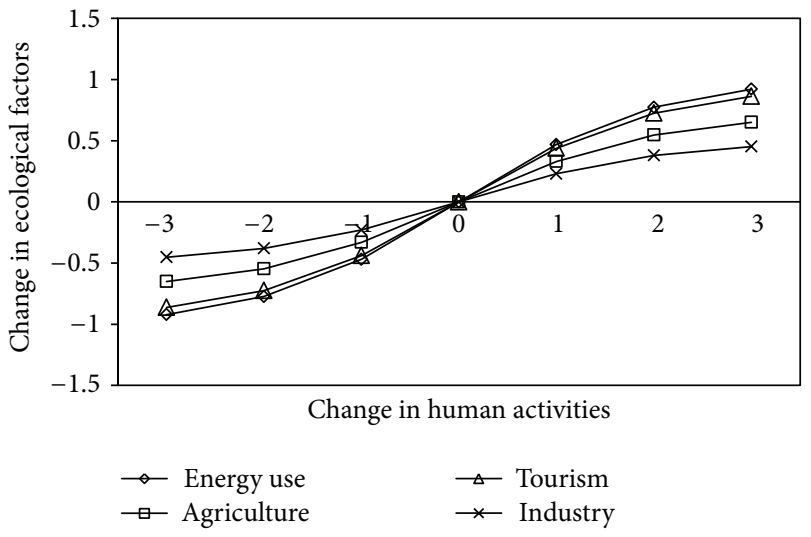

Figure 6: Changes in ecological factors as a function of human activities.

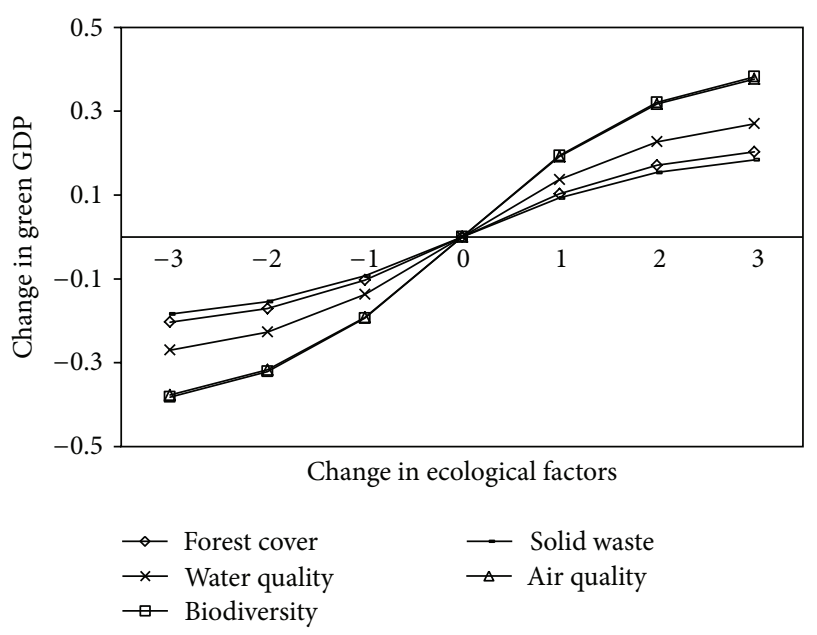

FIgURE 7: Changes in green GDP as a function of changes in ecological factors.

using a modified Pearl curve model. Firstly, this model was especially suitable for cities with a better environment, and we chose Wuyishan City as the case study. The industrialized city with heavy environmental pollution is not applicable in this model. Moreover, the AHP method may have some subjective as using scoring, and its combination with Pearl curve model is to realize the dynamic qualitative analysis. The quantitative analysis needs further study. 
TABLE 10: Standards for changes in green GDP as a function of ecological factors.

\begin{tabular}{|c|c|c|c|c|c|}
\hline & \multicolumn{5}{|c|}{ Green GDP changes for Wuyishan City } \\
\hline & Forest cover & Biodiversity & Air quality & Water quality & Solid waste \\
\hline $\mathrm{HD}(-3)$ & $-0.203 L_{2}$ & $-0.382 L_{2}$ & $-0.377 L_{2}$ & $-0.270 L_{2}$ & $-0.184 L_{2}$ \\
\hline $\mathrm{MD}(-2)$ & $-0.171 L_{2}$ & $-0.321 L_{2}$ & $-0.317 L_{2}$ & $-0.227 L_{2}$ & $-0.154 L_{2}$ \\
\hline $\operatorname{SD}(-1)$ & $-0.103 L_{2}$ & $-0.194 L_{2}$ & $-0.192 L_{2}$ & $-0.137 L_{2}$ & $-0.093 L_{2}$ \\
\hline $\mathrm{R}(0)$ & $0.000 L_{2}$ & $0.000 L_{2}$ & $0.000 L_{2}$ & $0.000 L_{2}$ & $0.000 L_{2}$ \\
\hline SI (1) & $0.103 L_{2}$ & $0.194 L_{2}$ & $0.192 L_{2}$ & $0.137 L_{2}$ & $0.093 L_{2}$ \\
\hline $\mathrm{I}(2)$ & $0.171 L_{2}$ & $0.321 L_{2}$ & $0.317 L_{2}$ & $0.227 L_{2}$ & $0.154 L_{2}$ \\
\hline EI (3) & $0.203 L_{2}$ & $0.382 L_{2}$ & $0.377 L_{2}$ & $0.270 L_{2}$ & $0.184 L_{2}$ \\
\hline
\end{tabular}

TABLE 11: Changes in green GDP as a function of changes in human activities.

\begin{tabular}{lcccc}
\hline & \multicolumn{3}{c}{ Green GDP changes for Wuyishan City } \\
& Energy use & Agriculture & Tourism & Industry \\
\hline HD (-3) & -0.257 & -0.182 & -0.241 & -0.126 \\
MD (-2) & -0.182 & -0.129 & -0.170 & -0.089 \\
SD (-1) & -0.067 & -0.047 & -0.062 & -0.033 \\
R (0) & 0.000 & 0.000 & 0.000 & 0.000 \\
SI (1) & 0.067 & 0.047 & 0.062 & 0.033 \\
I (2) & 0.182 & 0.129 & 0.170 & 0.089 \\
EI (3) & 0.257 & 0.182 & 0.241 & 0.126 \\
\hline
\end{tabular}

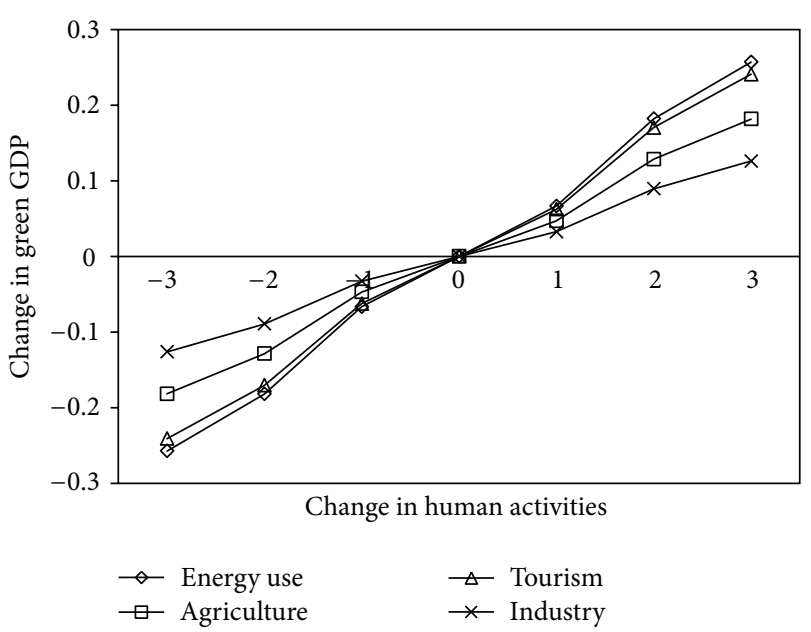

FIGURE 8: Changes in green GDP for Wuyishan City as a function of changes in human activities.

\section{Conclusion}

We proposed a model of the environment and resources planning and management based on a mathematical green GDP accounting method, which incorporated ecosystem services. This method can reflect the comprehensive state of a city, both in terms of the economy and environment, as well as understanding their implications for urban ecological regulation. This method is more suitable for cities with better natural environmental conditions; in this paper, the method was used to calculate the green GDP for Wuyishan City.
The DES value for Wuyishan City increased less, which was from 1.39 billion yuan in 2005 to 1.43 billion yuan in 2010. While the green GDP in Wuyishan City has risen much, which was from 4.41 billion yuan in 2005 to 8.01 billion yuan in 2010 .

To improve the urban environment and resource development, a model for identification of sensitive urban factors was put forward based on green GDP accounting. The sensitivity analysis of factors influencing the green GDP of Wuyishan City was conducted using an AHP method and the Pearl curve model. The results show that energy use is the key factor that influences the ecological function of the Wuyishan urban ecosystem. Moreover, biodiversity and air quality are the most important factors influencing green GDP in terms of ecosystem services. Guided by the analysis, six ecological projects were put forward for ecological function regulation to promote urban sustainable development; these proposed projects were water system corridor construction, special park construction, ecological landscapes restoration, rural biogas planning, vehicle control and improvement, and industrial energy structure adjustment. If these projects are implemented, the green GDP of Wuyishan City should gradually increase in the future.

In conclusion, green GDP can be considered as an indicator of the degree of sustainable urban development. The sensitivity analysis model based on green GDP accounting can be used in the context of urban environmental and resource planning.

\section{Appendix}

The 20 industry categories of the National Bureau of Statistics (NBS) are as follows.

(A) Agriculture, forestry, animal husbandry, and fishery.

(B) Mining.

(C) Manufacture.

(D) Electricity, gas and water production, and supply industry.

(E) Construction.

(F) Traffic transportation, storage, and postal services.

(G) Information transmission, computer services, and software industry. 
(H) Wholesale and retail business.

(I) Hotels, and catering services.

(J) Banking business.

(K) Realty business.

(L) Leasing and business services.

(M) Scientific research, technical services, and geological investigation industry.

(N) Water conservation, environmental, and public facilities management.

(O) Resident services and other services.

(P) Education.

(Q) Sanitation, social security, and social welfare.

(R) Culture, sports, and entertainment.

(S) Public administration and social organizations.

(T) International organizations.

\section{Acknowledgments}

This project is supported by the Fund for Innovative Research Group of the National Natural Science Foundation of China (Grant no. 51121003) and the National Science \& Technology Pillar Program, China (no. 2012BAC05B02).

\section{References}

[1] X. H. Yuan, X. Ji, H. Chen, B. Chen, and G. Q. Chen, "Urban dynamics and multiple-objective programming: a case study of Beijing," Communications in Nonlinear Science and Numerical Simulation, vol. 13, no. 9, pp. 1998-2017, 2008.

[2] M. Alberti, Advances in Urban Ecology: Integrating Humans and Ecological Processes in Urban Ecosystems, Springer, New York, NY, USA, 2008.

[3] M. J. McDonnell, A. Hahs, and J. Breuste, Ecology of Cities and Towns: A Comparative Approach, Cambridge University Press, New York, NY, USA, 2009.

[4] Y. P. Cai, G. H. Huang, and Q. Tan, "An inexact optimization model for regional energy systems planning in the mixed stochastic and fuzzy environment," International Journal of Energy Research, vol. 33, no. 5, pp. 443-468, 2009.

[5] Q. Tan, G. H. Huang, and Y. P. Cai, "A superiority-inferioritybased inexact fuzzy stochastic programming approach for solid waste management under uncertainty," Environmental Modelling and Assessment, vol. 15, no. 5, pp. 381-396, 2010.

[6] E. S. Svendsen and L. Campbell, "Urban ecological stewardship: understanding the structure, function and network of community-based urban land management," Cities and the Environment, vol. 1, no. 1, pp. 1-32, 2008.

[7] M. Ignatieva, G. H. Stewart, and C. Meurk, "Planning and design of ecological networks in urban areas," Landscape and Ecological Engineering, vol. 7, no. 1, pp. 17-25, 2011.

[8] J. Boyd, "Nonmarket benefits of nature: what should be counted in green GDP?" Ecological Economics, vol. 61, no. 4, pp. 716-723, 2007.

[9] L. Y. Xu, B. Yu, and W. C. Yue, "A method of green GDP accounting based on eco-service and a case study of Wuyishan, China," Procedia Environmental Sciences, vol. 2, pp. 1865-1872, 2010.
[10] G. Heal, "Environmental accounting for ecosystems," Ecological Economics, vol. 61, no. 4, pp. 693-694, 2007.

[11] R. Costanza, R. d'Arge, R. de Groot et al., "The value of the world's ecosystem services and natural capital," Nature, vol. 387, no. 6630, pp. 253-260, 1997.

[12] R. Costanza, "Social goals and the valuation of ecosystem services," Ecosystems, vol. 3, no. 1, pp. 4-10, 2000.

[13] R. Costanza, I. Kubiszewski, D. Ervin et al., "Valuing ecological systems and services," F1000 Biology Reports, vol. 3, no. 1, article 14, 2011.

[14] Millennium Ecosystem Assessment, Ecosystems and Human WellBeing: Synthesis, Island Press, Washington, DC, USA, 2005.

[15] J. Boyd and S. Banzhaf, "What are ecosystem services? The need for standardized environmental accounting units," Ecological Economics, vol. 63, no. 2-3, pp. 616-626, 2007.

[16] J. E. Stiglitz, A. Sen, and J. P. Fitoussi, "Report of the commission on the measurement of economic performance et social progress," 2009, http://www.stiglitz-sen-fitoussi.fr/en/index .htm.

[17] SEPA, "Report on green national economic accounting in China, 2004," Environmental Protection, vol. 18, pp. 22-29, 2006 (Chinese).

[18] D. Guan, W. Gao, W. Su, H. Li, and K. Hokao, "Modeling and dynamic assessment of urban economy-resource-environment system with a coupled system dynamics - geographic information system model," Ecological Indicators, vol. 11, no. 5, pp. 13331344, 2011.

[19] V. Mahajan and R. A. Peterson, "Integrating time and space in technological substitution models," Technological Forecasting and Social Change, vol. 14, no. 3, pp. 231-241, 1979.

[20] J. Baker, X. Ruan, A. Alcantara et al., "Density-dependence in urban housing unit growth: an evaluation of the Pearl-Reed model for predicting housing unit stock at the census tract level," Journal of Economic and Social Measurement, vol. 33, no. 2-3, pp. 155-163, 2008.

[21] W. C. Yue, L. Y. Xu, and X. Zhao, "Research of green GDP accounting in Wuyishan City based on ecosystem services," Ecological Economy, vol. 2, pp. 11-12, 2009 (Chinese). 


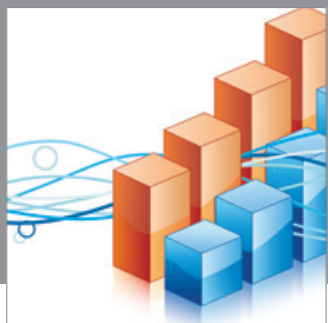

Advances in

Operations Research

mansans

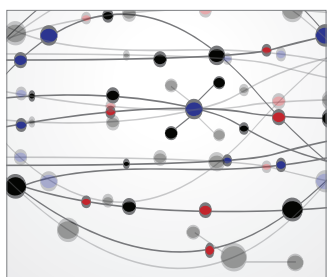

The Scientific World Journal
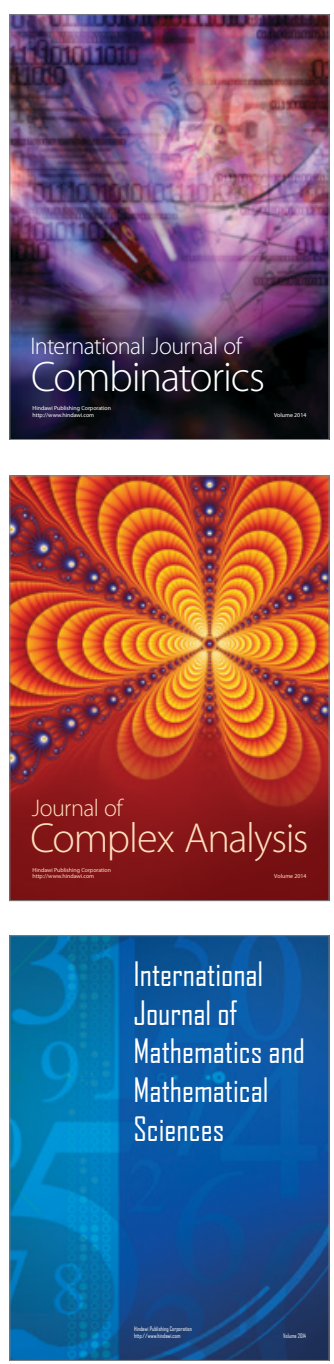
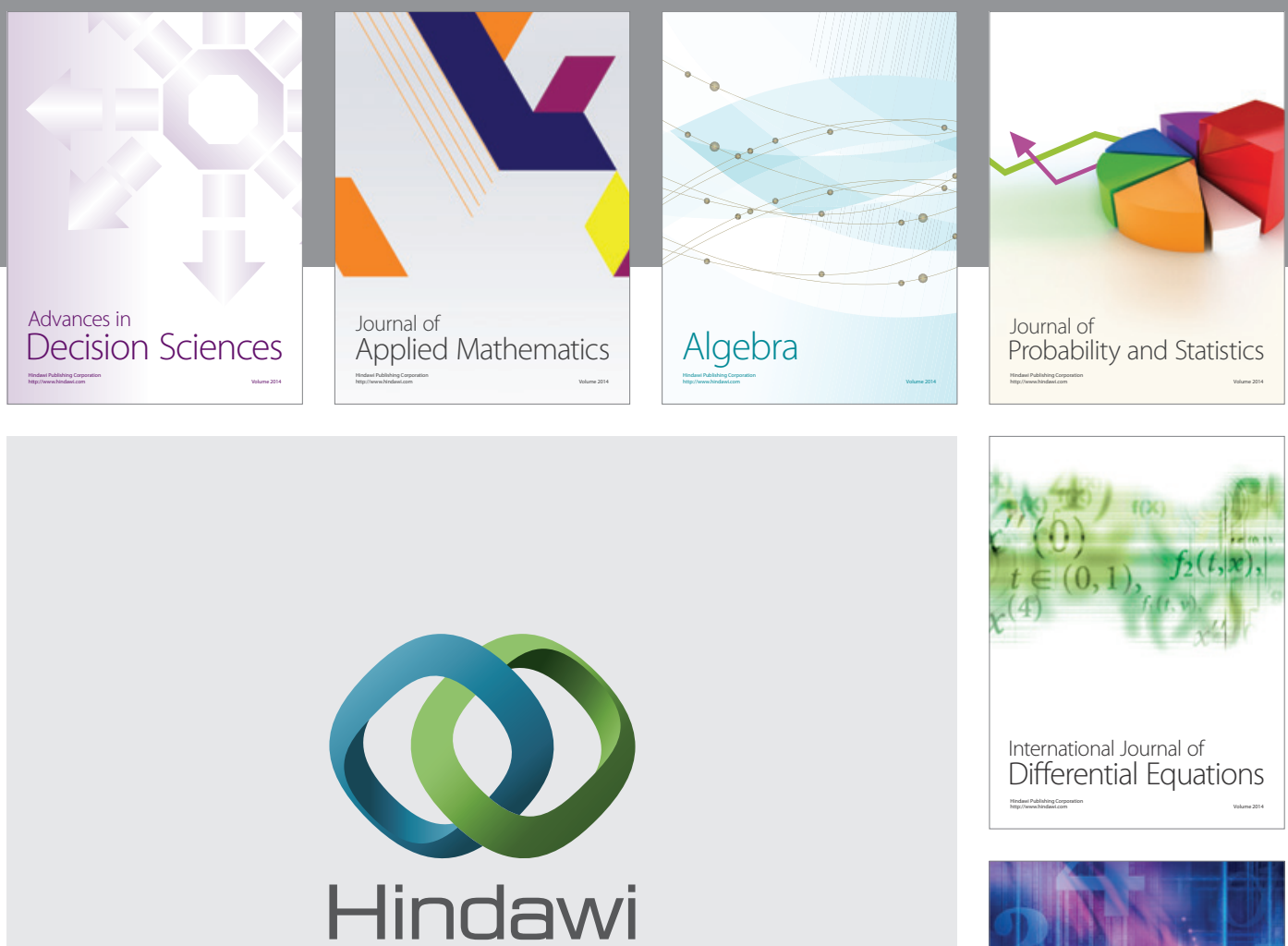

Submit your manuscripts at http://www.hindawi.com
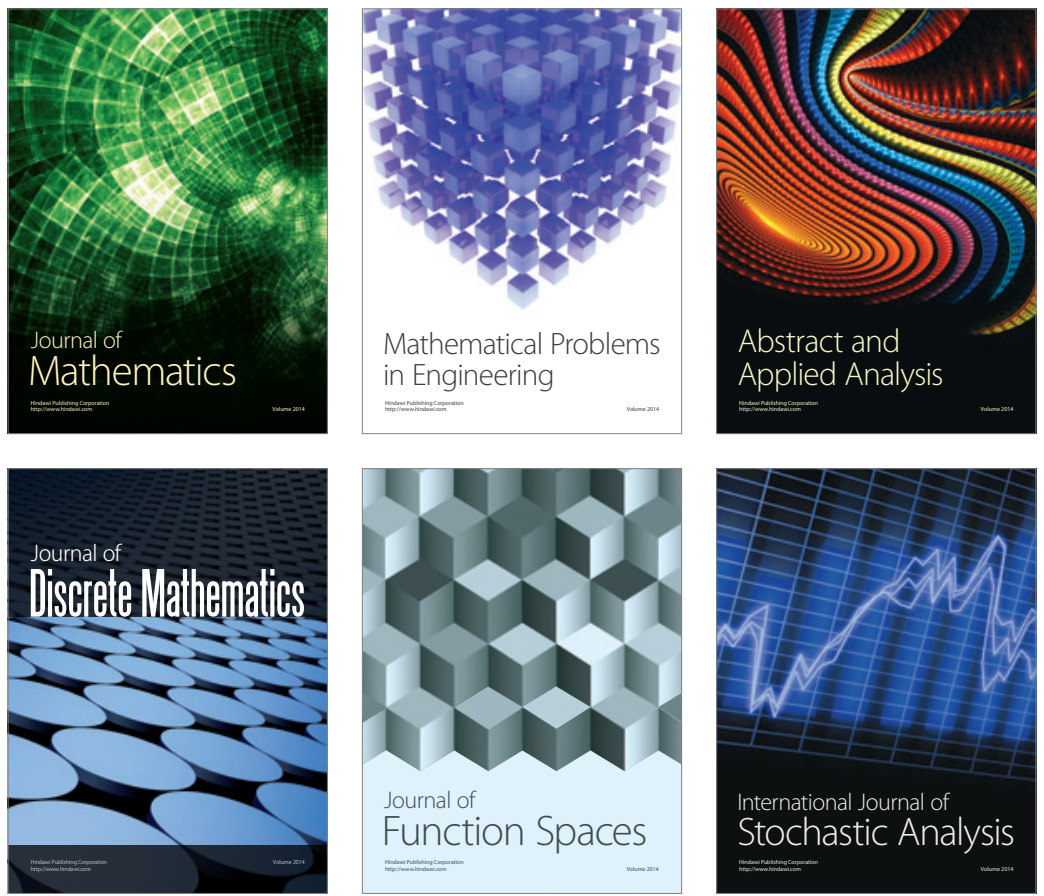

Journal of

Function Spaces

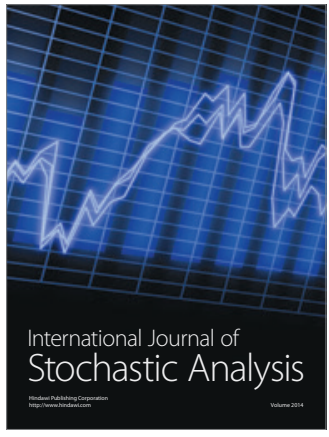

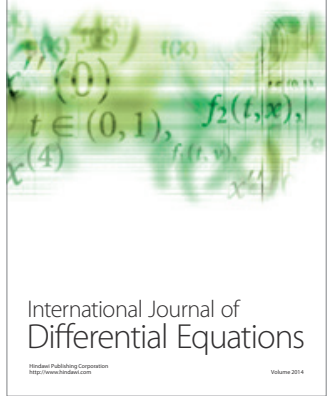
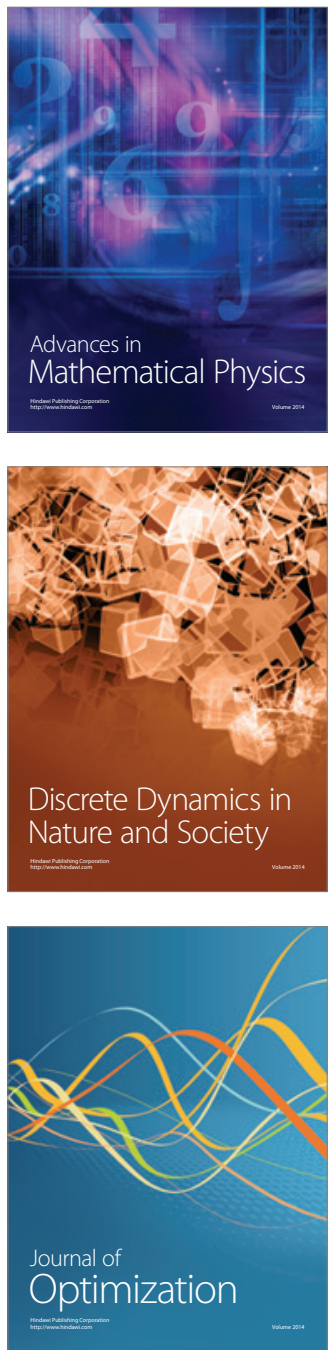